\title{
Feeding ecology of the European wildcat Felis silvestris in Portugal
}

\author{
Pedro SARMENTO
}

\begin{abstract}
Sarmento P. 1996. Feeding ecology of the European wildcat Felis silvestris in Portugal. Acta Theriologica 41: 409-414.

The feeding ecology of the European wildcat Felis silvestris Schreber, 1777 was studied by analysing 220 scats collected between January and December 1994 at Serra da Malcata Nature Reserve (Portugal). Feeding trials, carried out with a captive male and female, allowed the author to relate the dry excreted weight of prey items in the scats with the fresh biomass ingested. Rodents, particularly Apodemus silvaticus and Microtus lusitanicus, were the dominant component of the diet. Lagomorphs, mostly rabbit Oryctolagus cuniculus, were the second most heavily consumed item in terms of consumed biomass, being more preyed upon, in spring and summer. Although insectivores were regularly consumed throughout the year, this group only represented a small fraction of the total consumed biomass. Reptiles, especially species of Lacertidae, were the third most favoured quarry, with higher predator pressure in spring and summer. Bird remains were found at low levels throughout the year. Insects and plants were unimportant items in the diet. The wildcats feeding spectrum showed little variation throughout the year.
\end{abstract}

Reserva Natural da Serra da Malcata, Rua dos Bombeiros Voluntários s/n, 6090 Penamacor, Portugal; Fax: 07794580

Key words: Felis silvestris, diet, scat analysis, feeding trials, Portugal

\section{Introduction}

The European wildcat Felis silvestris Schreber, 1777 has a fragmented geographic distribution ranging from the Iberian Peninsula to the Middle East and also including the North of Scotland (Stahl and Leger 1992). Although is common in most of its distribution area several aspects of its biology remain unknown (Blanco and González 1992).

The wildcats feeding ecology has been mostly studied in France (Conde et al. 1972, Stahl 1986, Riols 1988), Scotland (Kolb 1977, Corbet 1979, Hewson 1983) and central Europe (Lindemann and Rieck 1953, Sládek 1973, Kožena 1990). In the Iberian Peninsula there have been only a few studies (Aymerich et al. 1980, Aymerich 1982).

This paper studies the composition and the seasonal fluctuations of the wildcats feeding spectrum and discusses the principal factors that influence its diet. This may contribute towards a better knowledge of the role this carnivore plays in the biocoenoses of the Mediterranean ecosystems. 


\section{Study area}

The study was carried out at Reserva Natural da Serra da Malcata (Portugal) situated between $40^{\circ} 08^{\prime} 50^{\prime \prime} \mathrm{N}-40^{\circ} 19^{\prime} 40^{\prime \prime} \mathrm{N}$ and $6^{\circ} 54^{\prime} 10^{\prime \prime} \mathrm{W}-7^{\circ} 09^{\prime} 14^{\prime \prime} \mathrm{W}$. This is a mountainous area, with elevations ranging from 430 to $1078 \mathrm{~m}$. The climate is characteristically Mediterranean and the temperatures range from a mean minimum of $0^{\circ} \mathrm{C}$ in January to a mean maximum of $30^{\circ} \mathrm{C}$ in July. The mean annual rainfall of $1000 \mathrm{~mm}$ falls mainly during winter between January and March. Vegetation is dominated by a dense maquis of Cytisus spp., Cistus ladanifer, Erica spp., Chamaespartium tridentatum, and Arbutus unedo, throughout which scattered individuals of Quercus rotundifolia and $Q$. pyrenaica can be found. Several parts of the study area are covered by industrial plantations of Pinus pinaster, P. nigra, Pseudotsuga menziezii, and Eucalyptos globulus.

\section{Material and methods}

\section{Wildcat diet}

Analyses of scats $(n=220)$ were used to determine the wildcats diet. Scats were collected along transects between January and December 1994 and identified by size, colour and odour.

The methodology of scat analysis was based on the methods described by Putman (1984) and Reynolds and Arbischer (1991). For analysis, scats were washed and sieved under a jet of water to separate undigested remains (fur, feathers, scales, bones and non-energetic plant material). The food items were weighed after drying in the air. The dry excreted weight and occurrence frequency of prey items (FO) were calculated for each faecal sample. The prey items considered were: rodents, insectivores, lagomorphs, reptiles, insects and plants.

Mammal remains were identified to the species level by using teeth and hairs (Debrot et al. 1982, Gállego and López 1982, Gállego and Alemany 1985, Teerink 1991). Mammal hairs were identified by general morphology, scale pattern, and medulla characteristics (Debrot et al. 1982, Teerink 1991).

If more than one mammal item were identified in a scat, the relative proportion of each was determined using the method described in Zins (1987). According to this method a random sample of fur $(n=10)$ is used to determine the frequencies of the different items by microscopic counting of hairs in fur cross sections. Item frequencies were multiplied by the total fur weight.

Bird remains were identified to the order level by microscopic analysis of the feathers (Day 1966). Reptiles were identified to the family or species level by using keys in Barbadillo (1987) and Arnold and Burton (1987) and a reference collection of reptile scales from the study area. Insects were identified to the order level by using keys in Chinery (1986) and a reference collection of insects from the study area.

\section{Feeding trials}

The feeding trials were carried out with a male wildcat (weighing about $6 \mathrm{~kg}$ ) and a female (weighing about $3.5 \mathrm{~kg}$ ) in captivity. The male was kept for 23 consecutive days and the female for 17. During this period they were both fed with natural prey. The proportions of the prey types used were identical to those which occur in the natural diet (Table 1). Each prey type was weighed and given to the wildcat once a day. The following day the faeces and the uneaten remains were collected and weighed.

Correction factors (CF), determined by feeding trials, were used to calculate the relative ingested biomass for the different prey items. The CFs (Table 2) were determined by dividing the total weight of consumed prey by the total dry weight of prey remains produced in the scats. The mean CFs (Table 2) multiplied by the dry weight of prey remains in the scat sample were used to determine the relative ingested biomass. To calculate the relative ingested biomass of Passeriformes and partridge the CFs of the female wildcat were used, since it was not possible to offered these preys to the male. 
Table 1. Proportions and weights of prey items offered to the wildcats during the feeding trials.

\begin{tabular}{|c|c|c|c|c|c|c|}
\hline \multirow{2}{*}{ Prey types } & \multicolumn{3}{|c|}{ Male } & \multicolumn{3}{|c|}{ Female } \\
\hline & $n$ & Mean weight (g) & SD & $n$ & Mean weight (g) & SD \\
\hline Rodents & 24 & 42.50 & 7.47 & 12 & 25.60 & 6.43 \\
\hline Rabbit & 2 & 510.10 & 21.21 & 2 & 870.00 & 190.95 \\
\hline Partridge & 0 & - & - & 1 & 270.00 & 0.00 \\
\hline Passeriformes & 0 & - & - & 1 & 27.00 & 0.00 \\
\hline Lizards & 1 & 95.00 & 0.00 & 2 & 50.00 & 14.14 \\
\hline Snakes & 1 & 554.00 & 0.00 & 1 & 36.00 & 0.00 \\
\hline
\end{tabular}

\section{Accuracy level of the sample}

Compared with the total number of produced scats, the analysis of a small sample of scats may be unrepresentative. The resulting error in assessing any aspect of the diet will depend on the variability between scats, and on the size of the sample (Reynolds and Aebischer 1991).

A pre-breeding wildcat density of 0.60 adults $/ \mathrm{km}^{2}$, determined by trapping techniques, and a defecation rate of 1.10 scats/day, determined by feeding trials, were estimated during the course of this study. The scats were collected in an area of $8 \mathrm{~km}^{2}$. Accordingly the number of scats produced by an adult per $\mathrm{km}^{2}$ per day would have been $0.66 \mathrm{scats} / \mathrm{km}^{2} /$ day or $1927 \mathrm{scats} / 8 \mathrm{~km}^{2} / 12$ months.

The size of the scat population from which we sampled is 1927 . From this value we calculated the $95 \%$ range of FO of the prey items in the analysed sample, using a form of the Monte Carlo simulation, according to the procedures described by Reynolds and Aebischer (1991).

\section{Results}

\section{Feeding trials}

All prey types, except rabbit Oryctolagus cuniculus and partridge Alectoris rufa, were devoured completely. The lower CFs were found between passeriformes and rodents, while rabbit, lizards and partridge presented the highests (Table 2). There were no significant differences between the CFs of the male and the female $\left(\chi^{2}=4.50, p>0.25\right)$.

Table 2. Feeding trial results. CF - correction factor, ${ }^{*}$ - only the CFs (female) were used to determine the relative consumed biomass of these two prey types.

\begin{tabular}{lccc}
\hline Prey types & CF (male) & CF (female) & Mean CF \\
\hline Rodents & 23.5 & 23.6 & 23.6 \\
Rabbit & 39.5 & 35.8 & 37.7 \\
Partridge & - & $42.2^{*}$ & - \\
Passeriformes & - & $15.5^{*}$ & - \\
Lizards & 40.3 & 41.2 & 40.7 \\
Snakes & 22.0 & 25.0 & 23.5 \\
\hline
\end{tabular}




\section{Wildcat diet}

The wildcat bases its diet upon animal prey. Plant material, essentially of the grass family, appeared in $21.2 \%$ of the scats (Table 3 ).

Rodents were the dominant component of the diet, being present in $92.9 \%$ of all scats and representing $55.0 \%$ of the total relative consumed biomass (Table 3, Fig. 1). Two species dominated the diet: Apodemus silvaticus $(\mathrm{FO}=71.3 \%)$ and Microtus lusitanicus $(\mathrm{FO}=35.4 \%)$. The wildcat preys regularly on these two rodent species throughout the year.

Present in $17.5 \%$ of the scats, lagomorphs were the second most heavily consumed item in terms of relative consumed biomass (28.7\%) (Table 3, Fig. 1). O. cuniculus apeared in $17.0 \%$ of the scats and Lepus granatensis in $0.5 \%$. The abundance of lagomorphs in the wildcats diet increased greatly in spring and summer (Fig. 1) as the rabbit populations increased and their juveniles became available.

Table 3. Diet of wildcats in the study area found in scat analysis. FO - frequency of ocurrence of prey items, $\mathrm{CB}$ - relative consumed biomass.

\begin{tabular}{lccc}
\hline Prey items & FO $(\%)$ & $95 \%$ range of FO $(\%)$ & CB $(\%)$ \\
\hline Rodents & 92.9 & $90.0-93.3$ & 55.0 \\
Lagomorphs & 17.5 & $15.9-21.1$ & 28.7 \\
Insectivores & 42.0 & $39.2-46.5$ & 3.0 \\
Birds & 27.4 & $25.9-29.2$ & 5.0 \\
Reptiles & 29.7 & $24.5-31.7$ & 8.3 \\
Insects & 2.7 & - & - \\
Plants & 21.2 & - & - \\
\hline
\end{tabular}

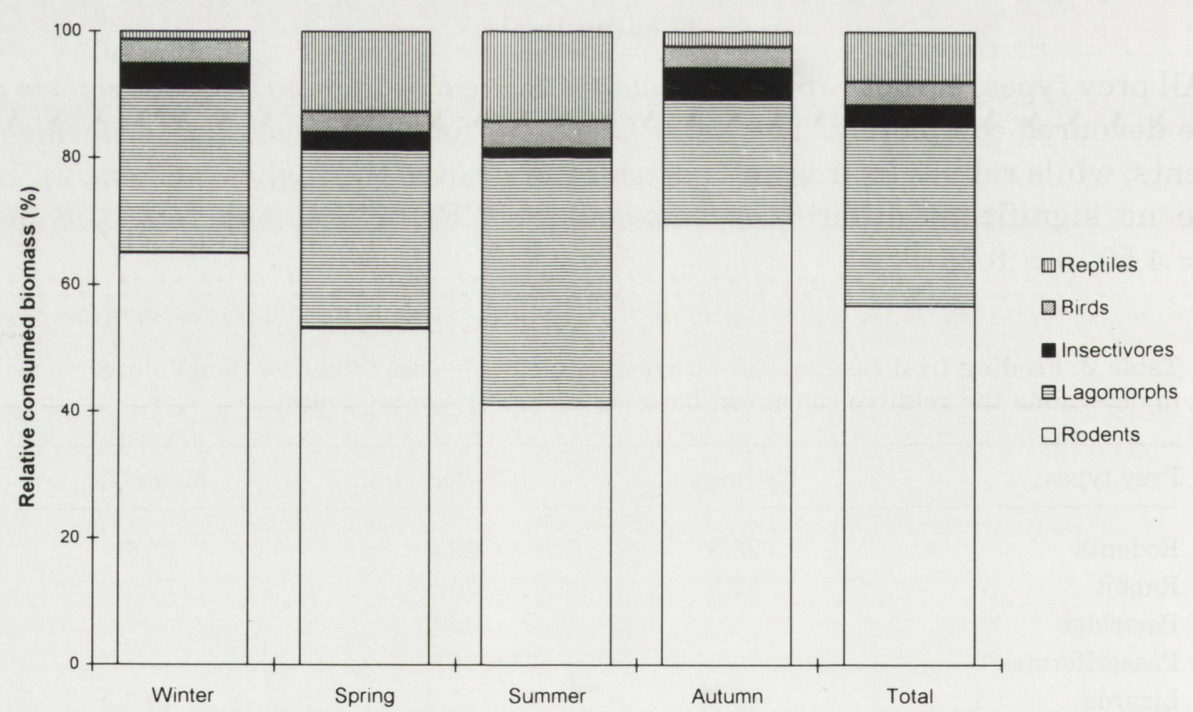

Fig. 1. Seasonal variation of the wildcat diet in Serra da Malcata Nature Reserve (Portugal). 
Reptiles, particularly species belonging to the Lacertidae, were the third most consumed quarry (Table 3, Fig. 1). Consumption of reptiles peaked in spring and summer, when they are more abundant, and declined throughout autumn (Fig. 1).

In the insectivore group, Crocidura russula $(\mathrm{FO}=28.3 \%)$ was the one that presented the highest predatory pressure. Although this group was constantly consumed throughout the year, it only represented $3.0 \%$ of the relative consumed biomass (Table 3, Fig. 1).

Bird remains were found in low levels throughout the year and there was no obvious seasonal pattern (Table 3, Fig. 1). The Passeriformes were the most heavily consumed $(\mathrm{CB}=4.9 \%)$. Insects were an unimportant item in the diet (Table 3 ).

\section{Seasonal variation in the diet}

The Shannon-Weaver Diversity Index was used to measure the variation of the diet diversity along the year. In winter (January-March) it was 2.74 ( $n=50$ scats), increasing to $2.85(n=62)$ in spring (April-June) and $2.95(n=57)$ in summer (July-September), and decreasing to $2.44(n=51)$ in autumn (October-December). The diet of the wildcat had a low variation along the year (Fig. 1) with no differences between seasons ( $\mathrm{GO}=0.96, \mathrm{~V}=0.48, p<0.005)$ (Ludwing and Reynolds 1988).

\section{Discussion}

The wildcat is a small-sized predator specialising in capturing mammals, especially rodents and lagomorphs. Rodents, as in other studies (Lindemann and Rieck 1953, Conde et al. 1972, Sládek 1973, Hewson 1983, Stahl 1986, Riols 1988, Kožena 1990), dominated the diet. Lagomorphs comsuption assumes greater importance with increasing availability in the environment. This fact may point to an economy in the predatory effort considering that wildcats feeding on rodents have to perform various daily captures unnecessary when they prey on lagomorphs. In this case a single capture can satisfy their daily energetic needs. The marked seasonal variation in the consumption of lagomorphs can be explained by seasonal changes in the relative abundance of the taxa and by their relative accesibility.

The diet of the wildcat in southwestern Spain (Aymerich et al. 1980, Aymerich 1982) was very similar to that found in this study. Rodents and lagomorphs also appeared as the dominant components of the diet. However, in these two studies there were more lagomorphs. Aymerich et al. (1980) determined FO $=28.6 \%$ and Aymerich (1982) $\mathrm{FO}=23.1 \%$ in the diet, while in the present study the value is $17.2 \%$. This variation may be explained by the higher lagomorph abundance in southwestern Spain (Blanco and Villafuerte 1993).

\section{References}

Arnold E. N. and Burton J. A. 1987. A field guide to the reptiles and amphibians of Britain and Europe. Collins, London: 1-275. 
Aymerich M. 1982. Etude comparative des régimes alimentaires du lynx pardelle (Lynx pardina Temminck, 1824) et du chat sauvage (Felis silvestris Schreber, 1777) au centre de la péninsule Ibérique. Mammalia 46: 515-521.

Aymerich M., Palacios P., Garzon J., Cuesta L. and Castroviejo J. 1980. Sobre la alimentación del gato montés (Felis silvestris Schreber, 1777) en España. Acta. I. Reuinón Iberoamericana de Zoologia de Vertebrados. La Rabida (Huelva): 543-544.

Barbadillo L. J. 1987. La guia de INCAFO de los Anfíbios y Reptiles de la Peninsula Iberica, Islas Baleares y Canarias. Incafo, S. A., Madrid: 1-694.

Blanco J. C. and González J. L. (eds) 1992. Libro rojo de los vertebrados de España. ICONA, Madrid: 657-659.

Blanco J. C. and Villafuerte R. 1993. Factores ecologicos que influyen sobre las poblaciones de conejos. Incidencia de la enfermedad hemorragica. Trag, SA: 1-66.

Chinery M. 1986. Insects of Britain and Western Europe. Collins, London: 1-320.

Conde B., Nguyen-Thi-Thu-Cuc, Vaillant F. and Schauenberg P. 1972. Le régime alimentaire du Chat forestier (Felis silvestris Schreber) en France. Mammalia 36: 112-119.

Corbett L. K. 1979. Feeding ecology and social organization of wildcats (Felis silvestris) and domestic cats (Felis catus) in Scotland. Unpublished Ph D Thesis, Aberdeen: 1-296.

Day M. G. 1966. Identification of hair and feather remains in the gut and faeces of stoats and weasels. Journal of Zoology, London 148: 275-286.

Debrot S., Mermod C. and Weber J. M. 1982. Atlas des poils de mammiféres d'Europe. Institut de Zoologie de l'Université de Neuchâtel, Neuchâtel: 1-208.

Gállego L. and Alemany A. 1985. Roedores e lagomorfos. Vertebrados Ibéricos 6: 1-64.

Gállego L. and López S. 1982. Mamíferos Insectívoros. Vertebrados Ibéricos 5: 1-62.

Hewson R. 1983. The food of wild cats (Felis silvestris) and red foxes (Vulpes vulpes) in west and north-east Scotland. Journal of Zoology, London 200: 283-289.

Kolb H. H. 1977. Wildcat. [In: The handbook of British mammals. G. B. Corbet and H. N. Southern, eds]. Blackwells Scientific Publishers, Oxford: 375-382.

Kožena I. 1990. Contribution to the food of wildcats (Felis silvestris). Folia Zoologica 39: 207-212.

Lindemann W. and Rieck W. 1953. Beobachtugen bei der Aufzucht von Wildkatzen. Zeitschrift für Tierpsychologie 10: 92-119.

Ludwing J. A. and Reynolds J. F. 1988. Statistical ecology. A primer on methods and computing. John Wiley \& Sons, New York: 111-124.

Putman R. Y. 1984. Facts from faeces. Mammal Review 14: 79-97.

Reynolds J. C. and Aebischer N. J. 1991. Comparison and quantification of carnivore diet by faecal analysis: a critique, with recommendations, based on a study of the Fox Vulpes vulpes. Mammal Review 21: 95-122.

Riols C. 1988. Etude du régime alimentaire du Chat forestier (Felis silvestris) dans l'est de la France. Bulletin Mensuel de l'Office National de la Chana 121: 22-27.

Sládek J. 1973. The quantitative composition of the food of the wildcat Felis silvestris living in West Carpathians. Biologia, Bratislava 28: 127-137.

Stahl P. 1986. Le chat forestier d'Europe (Felis silvestris Schreber, 1777): explotation des ressources et organization spatiale. Ph D thesis, University of Nancy, Nancy: 1-375.

Stahl P. and F. Leger 1992. Encyclopédie des carnivores de France, no. 17. Le chat forestier ou chat sauvage d'Europe. SFEPM: 1-50.

Teerink J. 1991. Hair of West-European Mammals. Atlas and identification key. Cambridge University Press, Cambridge: 1-244.

Zins C. 1987. Etude du regime alimentaire du renard (Vulpes vulpes L.) en Lorraine en fonction de la disponibillite en proies. Memoire de stage. Université des Sciences et Techniques de Lille: 1-60.

Received 15 April 1996, accepted 5 August 1996. 